\title{
Analysis and Classification of Channel Network Types for Intermittent Streams in the United Arab Emirates and Oman
}

\section{Jung $\mathrm{K}^{1 *}$ and Ouarda TBMJ ${ }^{1,2}$}

${ }^{1}$ Institute Center for Water and Environment, Masdar Institute of Science and Technology, Abu Dhabi, UAE

${ }^{2}$ Hydro-climatology Lab, INRS-ETE, University of Quebec, Quebec, Canada

\begin{abstract}
The mountainous region in the north of the United Arab Emirates (UAE) and Oman features intermittent streams called wadis which are generally dry but flow seasonally or temporarily. This region is characterized by high peaks and carbonate rocks. The main objective of the present study is to identify drainage network types for fifteen wadis in this northern region of the UAE and Oman. The slope of preexisting surfaces (preexisting slope) is also estimated to determine whether the preexisting slope affects the development of wadi networks. Drainage network types are determined by using three scaling-invariance measures: the drainage area increments, the channel course irregularity, and the tributary junction angle. The slope of preexisting surfaces is estimated based on small drainage areas and Laplace curvatures that are close to zero. In this study, thirteen wadis are classified as rectangular networks and two wadis are classified as parallel networks. Parallel networks are found to occur on steep preexisting slopes similarly to other regions in the world. Rectangular networks are also found to develop on steep preexisting slopes, whereas in other locations, such as in the USA, the same network type occurs on gentle preexisting slopes. This indicates that the development of rectangular networks in the region may be unaffected by preexisting slopes.
\end{abstract}

Keywords: Intermittent stream; Preexisting slope; Parallel network; Rectangular network; Wadi network types; Wadi

\section{Introduction}

The United Arab Emirates (UAE) and Oman are located in the northeastern part of the Arabian Peninsula between longitudes $51^{\circ}$ and $60^{\circ} \mathrm{E}$ and latitudes $16^{\circ}$ and $28^{\circ} \mathrm{N}$. The climate of the countries features extremely hot and dry conditions. In the UAE, the average temperature is $40^{\circ} \mathrm{C}$ during the summer season and $25^{\circ} \mathrm{C}$ during the winter season $[1,2]$, and the mean annual precipitation is about $78 \mathrm{~mm}$ ranging from $40 \mathrm{~mm}$ in the southern regions to $160 \mathrm{~mm}$ in the northeastern mountains $[3,4]$. In Oman, temperatures reach about $50^{\circ} \mathrm{C}$ during the summer season, and the mean annual precipitation ranges from $75 \mathrm{~mm}$ in the lowlands to $300 \mathrm{~mm}$ in the mountains [5]. The geomorphologic characteristics of the countries consist of sand dunes, gravel plains, coastal zones, and mountains $[1,6,7]$.

The region of study is bordered by the UAE to the west, Oman to the south, the Gulf of Oman to the east and the Hormuz strait to the north. This region includes a mountain range that is located at the northern tip of the Arabian Peninsula. The geology of the mountainous region is very complex with steep gradients [8]. The annual rainfall in this mountainous area is higher than the desert and coastal regions. Rainfall events generate intermittent streams called wadis which temporarily flow in the usually dry streambeds for only some weeks or months annually [9]. The wadi network is shaped by the surrounding cliffs which form the highest peaks of the mountain range in the region [6]. Figure 1 shows the location of the study area based on a Shadedrelief map indicating the direction that a mountain slope faces in the UAE and Oman.

The characteristics of river networks depend on existing regional climatic and physiographic conditions when they develop. Among various network types, dendritic networks are tree-like with a wide network shape consisting of meandering channel courses and tributaries that join at moderately acute junction angles $[10,11]$. Dendritic networks are commonly generated by erosion processes on soft rocks with gentle regional slopes. Parallel networks are characterized by narrow network shape, straight channel courses and tributaries that merge at more acute junction angles $[10,12,13]$. Parallel networks generally occur on topographic surfaces characterized by high gradients. Rectangular networks consist of channel course irregularities that are primarily occurring at a large number of right angle bends and tributaries that sometimes join at nearly right angles $[11,12]$. Rectangular networks are created by superimposition on rock fracturing and intersecting faults. All these patterns develop also on inherited landscapes. Figure 2 mainly shows examples of dendritic networks (Figure 2a), parallel networks (Figure $2 \mathrm{~b}$ ), and rectangular networks (Figure 2c).

Due to the different properties of networks and their impact on the hydrologic regime, a number of studies were carried out in the literature to develop quantitative methodologies for the identification and characterization of drainage networks. Argialas et al. [14] presented a drainage network classification system using third-order channel networks to determine river network types. Ichoku and Chorowicz [15] used the digital elevation models (DEMs) to propose a classification system based on sixteen characteristics of networks. Mejia and Niemann [16] proposed a classification derived from scaling invariance by investigating fifty channel networks to characterize five network types including dendritic, parallel, and rectangular patterns. More recently, Kim and Jung [17] analyzed geometric features for drainage structures based on the fractal dimension of river networks.

Several quantitative studies have also sought to assess conditions which affect the development of different channel networks. It has been observed that dendritic networks occur in regions with little geological constraints and gentle topographic slopes, while parallel networks mainly occur in regions with steep topographic slopes by forming parallel paths $[10-13,18]$. In a more recent study, Jung et al. [19] used

${ }^{*}$ Corresponding author: Kichul Jung, Institute Center for Water and Environment Masdar Institute of Science and Technology, PO Box 54224, Masdar, Abu Dhabi, UAE, Tel: +971 503560732; E-mail: jkichul@masdar.ac.ae

Received July 05, 2015; Accepted August 04, 2015; Published August 14, 2015

Citation: Jung K, Ouarda TBMJ (2015) Analysis and Classification of Channel Network Types for Intermittent Streams in the United Arab Emirates and Oman. J Civil Environ Eng 5: 183. doi:10.4172/2165-784X.1000183

Copyright: ( 2015 Jung $\mathrm{K}$, et al. This is an open-access article distributed under the terms of the Creative Commons Attribution License, which permits unrestricted use, distribution, and reproduction in any medium, provided the original author and source are credited. 

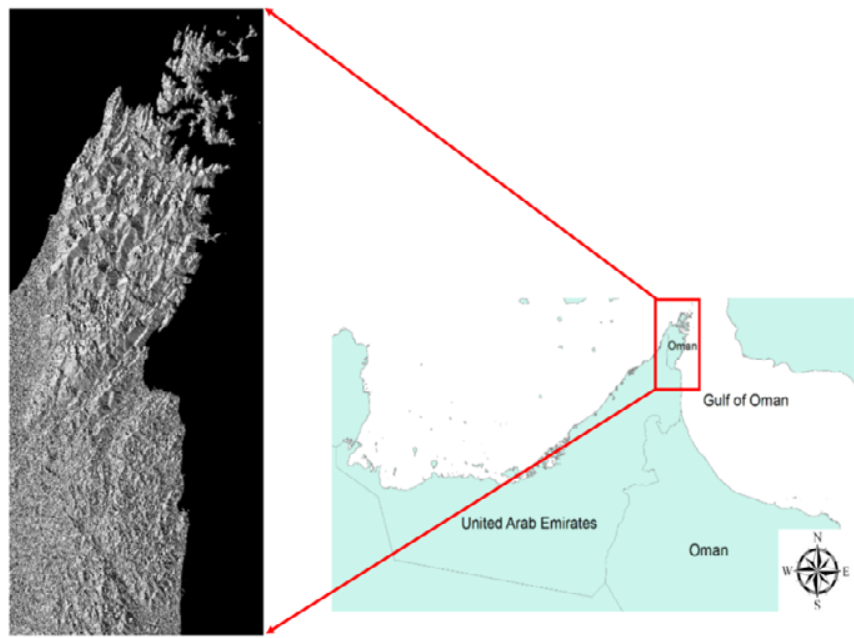

Figure 1: Location of the study area, represented by the red box, in the UAE and Oman. The figure on the left represents a Shaded-relief map indicating the direction to which a mountain slope faces. The study region is located between longitudes $55^{\circ} 57^{\prime} 14^{\prime \prime}$ and $56^{\circ} 33^{\prime} 15^{\prime \prime} \mathrm{E}$ and latitudes $25^{\circ} 5^{\prime} 10^{\prime \prime}$ and $26^{\circ} 25^{\prime} 16^{\prime \prime} \mathrm{N}$.
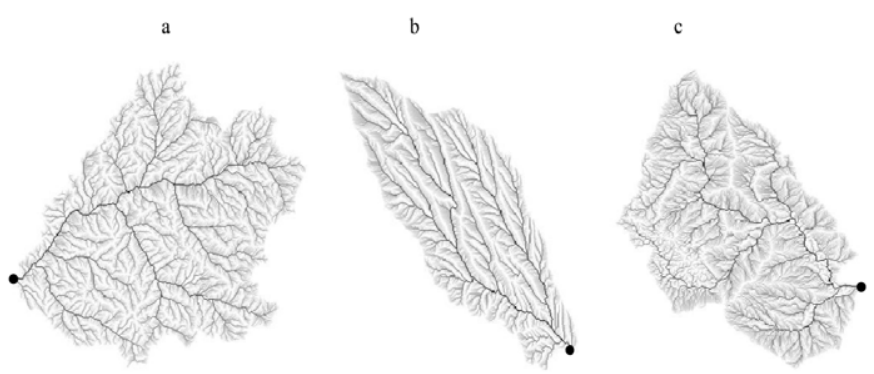

Figure 2: Three different drainage networks extracted from DEMs (a) Walker creek in Tennessee, USA, mainly showing a dendritic pattern, (b) Brundage Canyon in Utah, USA, a parallel pattern, and (c) Wadi Sal al a'la in Oman rectangular one. The black dot indicates the outlet of each basin.

the slopes of the preexisting surfaces (preexisting slopes) that are unaffected by the current evolution of hillslope and fluvial processes to evaluate the conditions under which different network types develop, based on river networks in the USA. They determined that parallel networks develop on steep preexisting slopes, whereas dendritic networks develop on gentle preexisting slopes. Rectangular networks are found in regions with the presence of cliffs, joints, or faults which meet at right angles $[11,12]$.

The analysis of drainage networks plays a significant role in the management of water resources as network characteristics are directly linked to the hydrologic processes taking place at the basin scale. Channel networks were shown to have implications on the downstream conveyance of water and sediments which are important for the design and construction of hydraulic structures [20], and sediments significantly affect the capacity of hydraulic structures with water flows [21,22]. River networks with their features such as basin area, main channel length, and mean basin slope have been widely used for hydrological applications including regional flood and lowflow frequency analysis [23-26]. Regional frequency analysis is used in the field of hydrology to transfer information from gauged stations to locations where little or no data are available, and in the design of hydraulic structures such as dams, reservoirs and control structures.

Although significant efforts have been made to investigate drainage networks in non-arid regions, the analysis of river networks was not conducted in arid and semi-arid regions in detail. Specifically, there is no study for the discrimination of drainage network types in the mountainous region of the Arabian Peninsula characterized by arid and semi-arid environments. It is also not clear under which conditions channel networks develop in the Arabian Peninsula.

The objectives of the present work are to distinguish between the different wadi network types in the UAE and Oman and to identify whether the slope of preexisting surfaces might affect the development of these wadis. The preexisting slope can affect the occurrence of different channel networks such as parallel or other related networks [19]. Based on the analysis of drainage networks, river network characteristics can be properly used in hydrological applications and in water resources management. The remainder of the paper is organized as follows: section 2 contains the discussion of methodologies used in the analysis. In section 3, we describe the data set used in the study. In section 4, the results of the analysis are presented. Finally, the conclusions and recommendations are presented in section 5 .

\section{Methodology}

\section{Calculation of the slope of preexisting surfaces}

The process to determine the slope of preexisting surfaces follows the method described in Jung et al. [19] to identify whether the preexisting slope influences the development of wadi networks. Preexisting surfaces considered to be relatively unaffected by the modern evolution of landscape are estimated based on two important thresholds. For the first threshold, the smallest drainage area of a channel network is used to determine channel head locations of hillslopes and to avoid points eroded by fluvial behavior. Discrimination between hillslopes and channels in drainage networks is performed based on a plot of the average slope versus the drainage area using a reverse point from positive representing hillslopes to negative indicating channels. Then, the Laplace curvature as the second threshold is calculated to identify preexisting surfaces using the following equation:

$$
\mathrm{k}=f_{\mathrm{xx}}+f_{\mathrm{yy}}
$$

Where $f_{\mathrm{xx}}$ and $f_{\mathrm{yy}}$ indicate the second-order derivatives of elevations for the directions of $x$ and $y$ in a basin of interest [27,28]. When modeling Laplace curvature, Evans [29] and Mitášová and Hofierka [28] indicated that a large concave-up curvature or a negative curvature is considered to be correlated with locations that fall within the valley network. A convex-up or a positive curvature, on the other hand, is considered to be associated with smooth regions produced by hillslope processes.

In this study, the values of thresholds for the curvature are revised, because no preexisting surfaces in wadis are observed when the thresholds of Jung et al. [19] are used. In the following, the thresholds of Jung et al. [19] are shown in parentheses next to the thresholds used in this study. In the region of study, one can expect that a point is eroded by evolution processes of landscape when the curvature of a point is below a threshold of $-0.006 / \mathrm{m}(-0.0008 / \mathrm{m})$. Scattered individual points are excluded by using another threshold of $-0.0062 / \mathrm{m}(-0.001 / \mathrm{m})$. Also, if the curvature exceeds a threshold of $0.006 / \mathrm{m}(0.0008 / \mathrm{m})$ a point is expected to be eroded by hill slope processes, and scattered individual points are excluded if the curvature of any adjacent neighbor exceeds a threshold of $0.0062 / \mathrm{m}(0.001 / \mathrm{m})$. If a given point is not identified by any of these thresholds, the point can be regarded as a part of the preexisting surfaces. Once the preexisting surfaces are determined, the average slope is calculated between each grid cell and its downstream neighbor in the preexisting surfaces. Due to the values of the thresholds 
which are close to zero, the resulting slopes of each grid cell between adjacent points will not be large. Note that the process for identification of preexisting surfaces is scale dependent as it depends on curvature calculation that is based on the resolution of the DEM data. Grid cells that are too large may neglect significant topographic features while grid cells that are too small may include irrelevant topographic features.

\section{Determination of drainage network type}

Several authors have investigated river basin morphology [30-32] and fractal river basins [33-35] to understand the river network system. In this study, the analysis of wadi networks based on fractal geometry is conducted to classify drainage network types in the UAE and Oman by using three measures of scaling invariance. Mejia and Niemann [16] proposed the use of measures based on the variation of the network geometry from a self-similar condition to a self-affine condition. In the self-similar condition, the horizontal characteristics of a subbasin seem to be statistically similar to the same properties of a large basin when the subbasin is isotropically rescaled. On the other hand, in the self-affine condition, the horizontal features of a subbasin tend to be statistically similar to the same properties of a large basin when the subbasin is anisotropically rescaled. If the self-affine condition applies, we can write

$$
\begin{aligned}
& \zeta_{\|}(L)={ }^{d} \mathrm{r}^{-1} \zeta_{\|}(r L) \\
& \zeta_{\perp}(L)={ }^{d} \mathrm{r}^{-\mathrm{H}} \zeta_{\perp}(r L)
\end{aligned}
$$

Where $L$ indicates the Euclidean distance. In this study, the Euclidean distance is linearly estimated from the outlet of a subbasin to the mainstream source of the network. This mainstream can be defined from the tributary of the larger drainage area at any junction in the network. The symbol $r$ means a rescaling factor in any given positive number, and the symbol $={ }^{d}$ stands for equality in distributions of both sides of the equations. A linear distance measured parallel to the longitudinal axis is denoted by $\zeta_{\|}(L)$ and a linear distance measured perpendicular to $\zeta_{\|}(L)$ is expressed by $\zeta_{\perp}(L)$. The self-affine parameter (Hurst exponent) is denoted by $H$ indicating the degree of anisotropy in the scaling condition. If $H$ is equal to the value of 1 , the self-similar condition holds. Based on the self-affine condition, three measures can be derived for classification of river networks.

The first measure is the incremental accumulation of drainage area. It is used to determine drainage network types of wadis. In this measure, if self-similarity holds in the horizontal characteristic of basin area $A$, the dimension of the channel network feature is equal to the value of 2 . Thus, one can write

$$
A(L)={ }^{d} r^{-2} A(r L)
$$

Based on the equation (4), a point between the basin outlet and its mainstream source is determined and an upstream point defined as $L-b L$, where $b$ is a constant factor, is identified using the Euclidean distance. The difference in the incremental areas between these two points can be denoted as $\Delta \mathrm{A}_{\mathrm{bL}}(L)$. If the self-similar condition holds, the probability distribution of $\Delta \mathrm{A}_{\mathrm{bL}}(L) / L^{2}$ is considered to be independent of $L$ for a fixed value of $b$ and a stationary process can be observed in a plot of $\Delta \mathrm{A}_{\mathrm{bL}}(L) / L^{2}$ versus $L$. On the other hand, if the self-affine condition holds for a given basin, the plot produces a constant slope which implies the Hurst exponent. The constant $b$ is a critical factor to define the scale of the measure of the drainage area increment. One can observe that the range of drainage sizes in the plot decreases when the constant $b$ becomes large. This is because the upstream point of the basin indicates a hillslope grid cell instead of a fluvial grid cell. If the constant $b$ becomes small, one can identify that the grid resolution affects the results of the measure of the drainage area increment since the segments only have a small number of grid cells. This behavior is observed in the region of this study. The value of $b=0.2$ is assigned to the increment of the drainage area on the basis of the analysis of Mejia and Niemann [16].

Stream course irregularity is applied to wadi networks for the identification of network types as the second measure. To estimate channel course irregularity, we determine a point defined by the Euclidean distance $L$ ranging from a mainstream source to its outlet and another point defined by the distance $L-L$ ranging from the source of an associated upstream location to the outlet. Then, the standard deviation of the lengths of channel courses is calculated between these two points by measuring a direction which is vertical to the longitudinal axis of a subbasin for the second measure. The corresponding equation is written as:

$$
\sigma_{\mathrm{b}}(L)={ }^{d} \mathrm{r}^{-1} \sigma_{\mathrm{bL}}(r L)
$$

Where $\sigma_{\mathrm{b}}(L)$ indicates the standard deviation of the lengths of the river courses. The distribution of $\sigma_{\mathrm{bL}}(L) / L$ is independent of $L$ when self-similarity holds so that a plot of $\sigma_{\mathrm{bL}}(L) / L$ versus $L$ can be stationary. This plot also produces a slope to estimate the Hurst exponent if the self-affine condition holds. The constant $b$ is found to be 0.4 for the measure of the stream course irregularity as in Mejia and Niemann [16].

The third measure is based on the angles identified from any location of the channels that merge junctions of two tributaries. For the first tributary, one can use the chord between the junction and a location formed by a distance $b L$ upstream from the junction on the larger tributary with the Euclidean distance $L$ calculated from the mainstream source of the larger tributary. For the secondary tributary, one can employ the chord between the junction and a location formed by a distance $b L_{\mathrm{s}}$ upstream from the junction on the smaller tributary with the Euclidean distance $L_{\mathrm{s}}$ calculated from the mainstream source of the smaller tributary. If the self-similar condition holds, we have:

$$
\psi_{b, b}(L)={ }^{d} \psi_{r b, r b}(r L)
$$

In this equation, the subscript of $\psi$ represents an important factor that is required to control the chord lengths in measuring the junction angle between the first and secondary tributaries. The angle is defined as the tributary junction angle which is described by $\psi_{b L, b L_{\mathrm{s}}}(L)$. The distribution of $\psi_{b L, b L_{\mathrm{s}}}(L)$ is independent of $L$ if the self-similar condition holds. However, due to the process of measuring $\psi_{b L, b L_{\mathrm{s}}}(L)$, a slope in the plot $\psi_{b L, b L_{\mathrm{s}}}(L)$ versus $L$ is not directly associated with the Hurst exponent and the slope does not produce the Hurst exponent. The value $b=0.1$ is selected as measure of the tributary junction angle based on the analysis of Mejia and Niemann [16].

\section{Data set}

Fifteen wadis are randomly chosen by using Google Earth with a topographical map including the coordinates and contour lines to be classified into drainage network types in the mountainous region of northeastern UAE and northern Oman. Figure 3 shows all fifteen wadi basins in the region of study. Ten wadis are located in the UAE and five wadis are located in Oman.

The selected wadis located in the north of the Ru'us al-jibal region, which is the mountainous Musandam peninsular in the UAE and Oman, feature the thick sequences of carbonate rocks and high peaks [36]. The distinctive geology of the area is the product of the regional uplift driven by plate tectonics and erosion proceeded by alternation of cutting and filling under arid and semi-arid conditions. To analyze the 


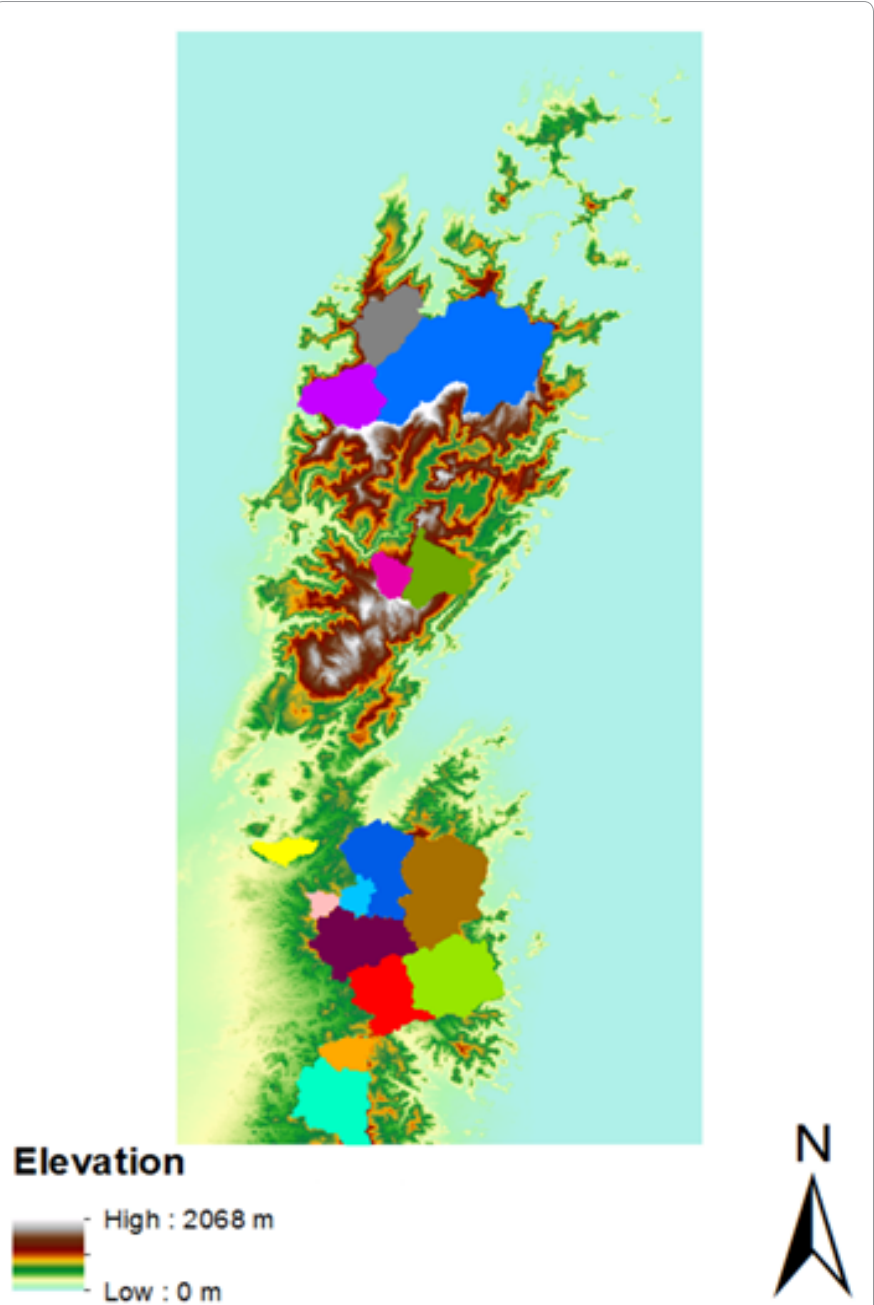

Figure 3: The 15 wadi basins selected for the study in the mountainous region of the UAE and northern Oman.

wadis, DEMs with approximately $30 \mathrm{~m}$ grid cells are acquired from the Global DEM derived from the data of Advanced Spaceborne Thermal Emission and Reflection Radiometer (ASTER) satellite. A resolution of $30 \mathrm{~m}$ is used in this study as it is the most common grid cell size for the earth surface analysis. Note that Mejia and Niemann [16] determined no influence in employing different resolutions for their analysis. The boundaries of the region analyzed in this study are as follows: at the North: $26.414023^{\circ}$, South: $25.0779013^{\circ}$, West: $55.968758^{\circ}$, and East: $56.570429^{\circ}$. In this region, the drainage networks of the watersheds were determined by calculating the flow directions and summing up the total areas draining through each grid cell based on the DEMs. Table 1 shows the basin sizes and the coordinates of the wadis analyzed in the study. Basin sizes range from 8.43 to $197.65 \mathrm{~km}^{2}$ for the fifteen wadis.

Once drainage network types are identified for the fifteen wadis in the UAE and Oman, river networks in other regions having the same pattern as the wadis are analyzed by providing the preexisting slope to identify whether the preexisting slope has an impact on the development of wadi networks. The river networks used to compare the preexisting slope were classified in the previous studies $[16,19]$. The DEMs characterized by the horizontal resolution of 1 arc-second with approximate $30 \mathrm{~m}$ grid cells for the river networks are obtained from the Seamless Data Distribution System (SDDS) of the United State Geological Survey (USGS).

\section{Results and Discussions}

\section{Preexisting surface slope}

The average slopes of preexisting surfaces for the fifteen wadis are estimated to assess the dependence of wadi networks on the preexisting slope when the wadi networks develop. Figure 4 presents an example of preexisting surfaces for the basin of Wadi Siji in the UAE. The proportion of preexisting surfaces in the wadi represents $1.30 \%$ of the whole basin area and the preexisting slope is $8.44 \%$.

Table 2 presents the preexisting slopes of the fifteen wadis, the drainage area thresholds and the drainage network types which are identified by using the three measures described in the methodology section. The preexisting slopes of wadis classified as rectangular networks range between $6.83 \%$ and $15.26 \%$ with an average of $12.01 \%$. The preexisting slopes of wadis classified as parallel network range between $8.47 \%$ and $11.31 \%$ with an average of $9.89 \%$. However, rectangular networks in non-arid regions of the USA identified by Zernitz [12] and Mejia and Niemann [16] feature an average preexisting slope of $2.70 \%$ which is considerably smaller than the observed average slope of the same network type in the present study area. It is probable that regional climatic and geographic characteristics lead to these different preexisting slopes and the result indicates that the development of rectangular networks may not be dependent on preexisting slopes. The wadi networks representing rectangular networks in the UAE and Oman might be developed by processes of erosion of the mountains and deposition of gravels proceeded by climate conditions. Climate conditions have an effect on the characteristics of wadi networks because erosion and deposition processes highly increase in wet climate conditions [36]. On the other hand, the development of rectangular networks in the USA is conditioned by the right-angled joining or faulting of rocks, and the rectangular networks are characterized by right-angled bends in the main stream and its tributaries [12]. The steep preexisting slopes of wadis representing parallel networks seem to be consistent with the preexisting slopes of parallel networks in other regions [19].

\section{Classification of wadi network types}

To classify drainage network types for the selected fifteen wadis, three measures derived from scaling invariance are used and the first measure is the drainage area increments. This measure is estimated for all locations in each wadi, and the results are sorted along with

\begin{tabular}{|c|c|c|}
\hline Wadi name & $\begin{array}{l}\text { Latitude and longitude of outlet } \\
\text { in degrees, Minutes, Seconds }\end{array}$ & Basin area $\left(\mathbf{k m}^{2}\right)$ \\
\hline Khassab, Oman & $26^{\circ} 5^{\prime} 25.00^{\prime \prime} \mathrm{N}, 56^{\circ} 15^{\prime} 28.00^{\prime \prime} \mathrm{E}$ & 197.65 \\
\hline Sal al a'la, Oman & $26^{\circ} 6^{\prime} 13.59^{\prime \prime} \mathrm{N}, 56^{\circ} 15^{\prime} 4.42^{\prime \prime} \mathrm{E}$ & 46.74 \\
\hline Bih, Oman & $25^{\circ} 43^{\prime} 45.87^{\prime \prime} \mathrm{N}, 56^{\circ} 16^{\prime} 2.92^{\prime \prime} \mathrm{E}$ & 44.13 \\
\hline Madhah trib. 1, Oman & $25^{\circ} 16^{\prime} 47.17^{\prime \prime} \mathrm{N}, 56^{\circ} 19^{\prime} 38.29^{\prime \prime} \mathrm{E}$ & 80.13 \\
\hline Madhah trib. 2, Oman & $25^{\circ} 22^{\prime} 55.24^{\prime \prime} \mathrm{N}, 56^{\circ} 18^{\prime} 7.56^{\prime \prime} \mathrm{E}$ & 101.17 \\
\hline Asimah, UAE & $25^{\circ} 23^{\prime} 44.28^{\prime \prime} \mathrm{N}, 56^{\circ} 8^{\prime} 35.31^{\prime \prime} \mathrm{E}$ & 13.11 \\
\hline Al Mawrid, UAE & $25^{\circ} 24^{\prime} 31.23^{\prime \prime} \mathrm{N}, 56^{\circ} 6^{\prime} 13.24^{\prime \prime} \mathrm{E}$ & 8.43 \\
\hline Al Fara, UAE & $25^{\circ} 17^{\prime} 52.84^{\prime \prime} \mathrm{N}, 56^{\circ} 7^{\prime} 26.44^{\prime \prime} \mathrm{E}$ & 63.66 \\
\hline Ghalilah, UAE & $25^{\circ} 58^{\prime} 28.60^{\prime \prime} \mathrm{N}, 56^{\circ} 5^{\prime} 56.81^{\prime \prime} \mathrm{E}$ & 51.16 \\
\hline Ham, UAE & $25^{\circ} 13^{\prime} 54.86^{\prime \prime} \mathrm{N}, 56^{\circ} 12^{\prime} 4.99^{\prime \prime} \mathrm{E}$ & 52.58 \\
\hline Siji, UAE & $25^{\circ} 13^{\prime} 24.69^{\prime \prime} \mathrm{N}, 56^{\circ} 8^{\prime} 51.24^{\prime \prime} \mathrm{E}$ & 63.66 \\
\hline Farfar, UAE & $25^{\circ} 11^{\prime} 50.19^{\prime \prime} \mathrm{N}, 56^{\circ} 8^{\prime} 23.80^{\prime \prime} \mathrm{E}$ & 19.32 \\
\hline Hayl, UAE & $25^{\circ} 9^{\prime} 46.84^{\prime \prime} \mathrm{N}, 56^{\circ} 5^{\prime} 13.57^{\prime \prime} \mathrm{E}$ & 89.33 \\
\hline Tayyibah, UAE & $25^{\circ} 28^{\prime} 43.47^{\prime \prime} \mathrm{N}, 56^{\circ} 11^{\prime} 16.46^{\prime \prime} \mathrm{E}$ & 60.42 \\
\hline Sanaa, UAE & $25^{\circ} 26^{\prime} 49.59^{\prime \prime} \mathrm{N}, 56^{\circ} 7^{\prime} 36.72^{\prime \prime} \mathrm{E}$ & 13.57 \\
\hline
\end{tabular}

Table 1: The 15 wadis analyzed in the study with outlet locations and basin sizes. 


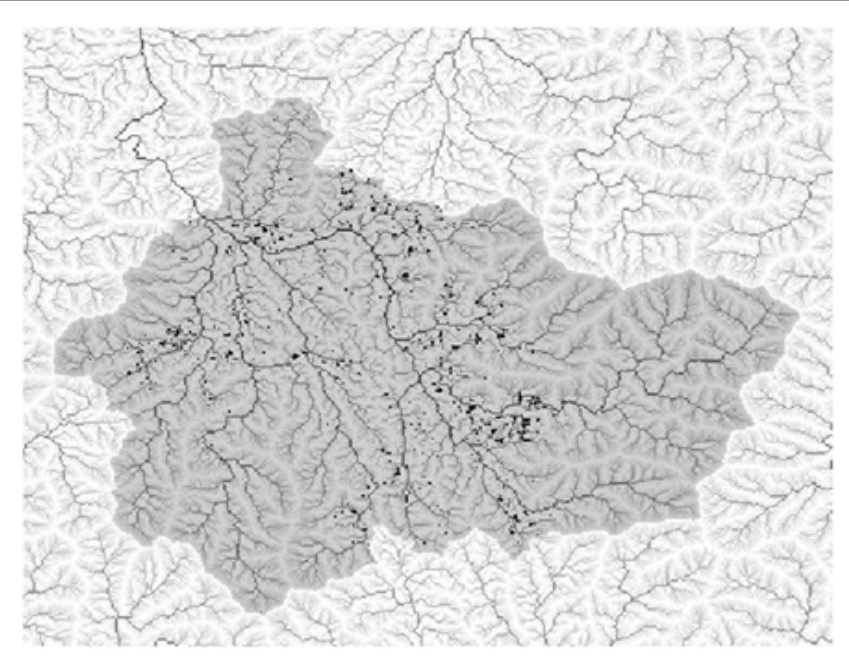

Figure 4: Illustration of regions of preexisting surfaces for Wadi Siji in the UAE. The average slope of preexisting surfaces is $8.44 \%$. Dark gray shading indicates the extent of a basin and black shading indicates the extent of the location of preexisting surfaces.

\begin{tabular}{|l|l|l|l|}
\hline Wadi name & Area threshold $\mathbf{( m}^{\mathbf{2}} \mathbf{)}$ & Preexisting slope (\%) & Network type \\
\hline Khassab & $2 \times 10^{3}$ & 11.89 & Rectangular \\
\hline Sal al a'la & $6 \times 10^{3}$ & 12.68 & Rectangular \\
\hline Ghalilah & $6 \times 10^{3}$ & 9.19 & Rectangular \\
\hline Bih & $6 \times 10^{3}$ & 18.23 & Rectangular \\
\hline Asimah & $2 \times 10^{3}$ & 6.83 & Rectangular \\
\hline Al Mawrid & $3 \times 10^{3}$ & 15.26 & Rectangular \\
\hline Al Fara & $4 \times 10^{3}$ & 8.60 & Rectangular \\
\hline Ham & $3 \times 10^{3}$ & 11.99 & Rectangular \\
\hline Madhah trib. 1 & $5 \times 10^{3}$ & 14.99 & Rectangular \\
\hline Madhah trib. 2 & $3 \times 10^{3}$ & 15.30 & Rectangular \\
\hline Siji & $4 \times 10^{3}$ & 8.44 & Rectangular \\
\hline Farfar & $5 \times 10^{3}$ & 10.52 & Rectangular \\
\hline Hayl & $5 \times 10^{3}$ & 12.23 & Rectangular \\
\hline Tayyibah & $3 \times 10^{3}$ & 11.31 & Parallel \\
\hline Sanaa & $3 \times 10^{3}$ & 8.47 & Parallel \\
\hline
\end{tabular}

Table 2: The 15 wadis with the area thresholds to identify preexisting locations, the average slope of preexisting surfaces, and drainage network types.

the corresponding Euclidean basin lengths. In Figure 5a, the average drainage area increment is illustrated as a function of the Euclidean length along with the regression lines for five wadis. These five wadis are selected to represent both rectangular and parallel networks. Rectangular networks seem to have approximately horizontal lines, whereas parallel networks seem to have negative slopes.

Figure $5 \mathrm{~b}$ illustrates the preexisting slopes of all fifteen wadis with the associated Hurst exponents. The vertical dashed line represents the threshold for the preexisting slope of $2.85 \%$ proposed by Jung et al. [19] to assess whether the preexisting slope influences the development of different drainage networks. The horizontal dashed line indicates a threshold of the Hurst exponent of 0.91 to determine self-similar and self-affine conditions in channel networks [16]. These thresholds can be used to identify the drainage network types in this study region since they can be considered as standard and are not dependent on regional conditions. It is observed that the thirteen wadis classified as rectangular networks (self-similar networks) are located above the horizontal line with Hurst exponent values ranging between 0.91 and 1.33 and an average Hurst exponent of 1.02. The two wadis classified as parallel networks (self-affine networks) are located below the horizontal line with Hurst exponent values ranging between 0.74 and 0.83 and an average Hurst exponent of 0.79 . The results are consistent with the previous study for self-similar and self-affine networks [19]. All wadi networks analyzed in the present work have steep preexisting slopes.

The measure of the irregularity of stream courses is also applied to the same fifteen wadis to classify drainage networks. Figure 6a illustrates the results for the same five wadis presented in the analysis of drainage area increments. In Figure 6a, the plots seem to be approximately horizontal for rectangular networks and tend to have negative slopes for parallel networks.

Figure $6 \mathrm{~b}$ shows the estimates of the Hurst exponent using the stream course irregularity against the associated preexisting slopes for all fifteen wadis. The average estimate of the Hurst exponent is 1.03 (range: 0.91-1.21) for the thirteen wadis classified as rectangular networks, and the average estimate of the Hurst exponent is 0.76 (range: $0.72-0.81$ ) for the two wadis classified as parallel networks. It should be noted that the average estimate of the stream course irregularity can be used to identify the presence of rectangular networks, once drainage networks are determined as self-similar. If the average value calculated by the measure of the channel course irregularity is larger than 0.0175 , drainage networks are considered to be rectangular networks [16]. On

a

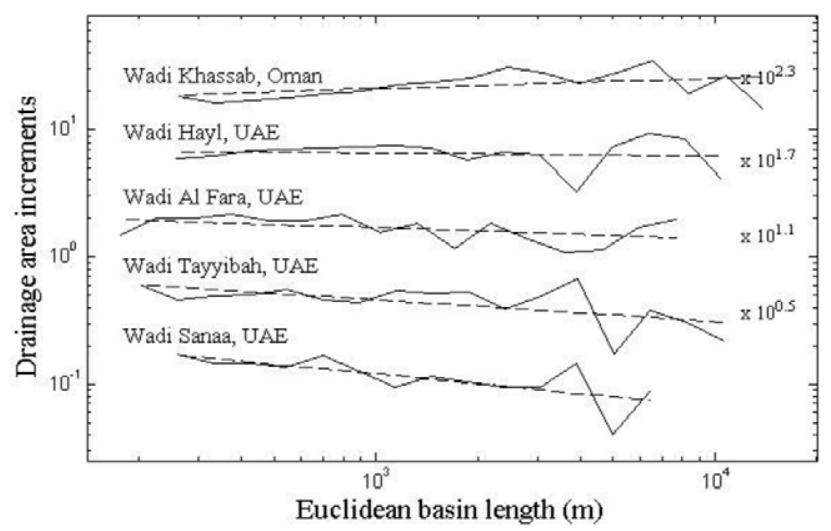

$\mathrm{b}$

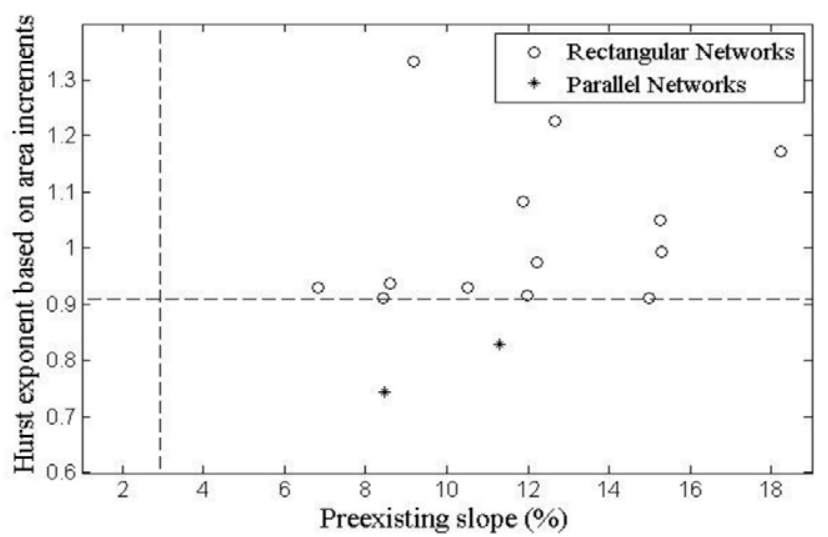

Figure 5: Figure (a) indicates the average value of the drainage area increment $\Delta A_{b L}(L) / L^{2}$ as a function of the Euclidean basin length for 5 wadis, and the dashed lines are regression ones fitted to the data. Figure (b) illustrates the relationship between the Hurst Exponent and the preexisting slope for all 15 wadis, and the thresholds are used to classify different networks. 

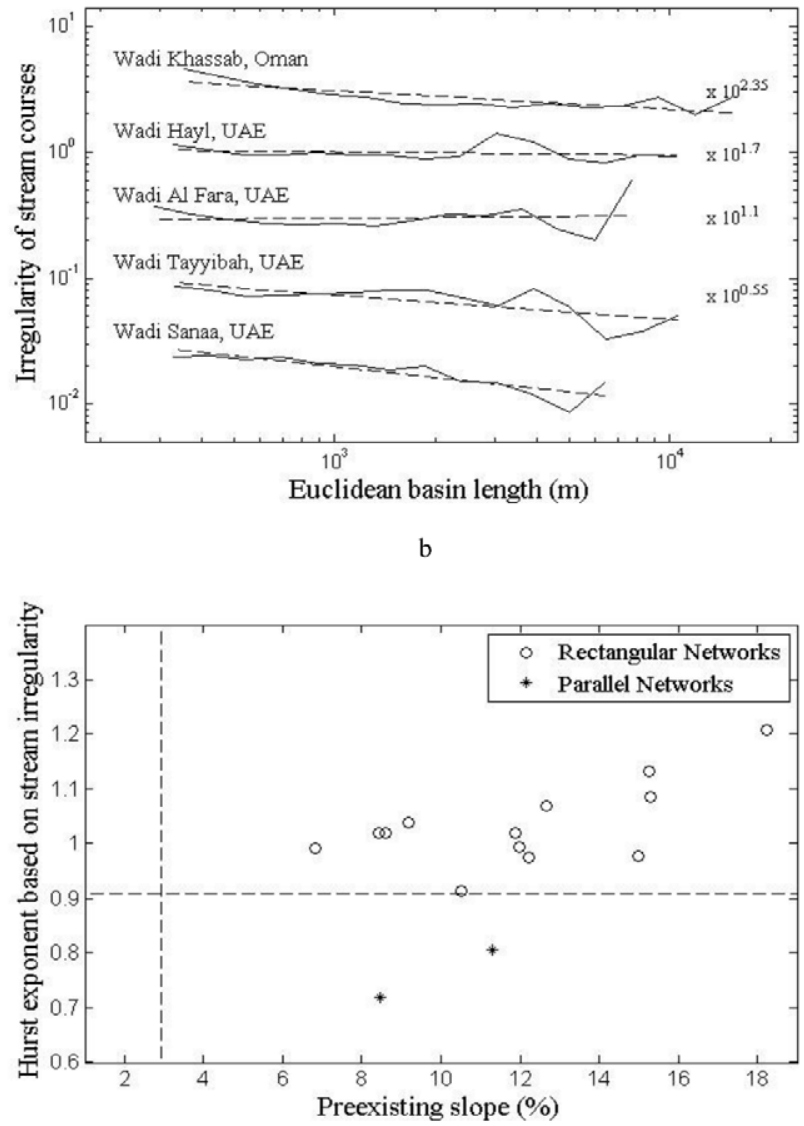

Figure 6: Figure (a) indicates the average value of the channel course irregularity $\sigma_{b L}(L) / L$ as a function of the Euclidean basin length for 5 wadis, and the dashed lines are regression ones fitted to the data. Figure (b) illustrates the relationship between the Hurst Exponent and the preexisting slope for all 15 wadis, and the thresholds are used to distinguish between different network types.

the order hand, river networks can be regarded as dendritic networks when the average value of the stream course irregularity is smaller than 0.0175 [16]. The average estimate of the stream course irregularity for the thirteen wadis representing rectangular networks is 0.0214 (range: $0.0176-0.0248$ ). Most of the wadis examined in the UAE and Oman in this study tend to represent rectangular networks.

The third measure is the tributary junction angle to determine the channel network types of the fifteen wadis. Figure 7 a illustrates the regression lines of this measure as a function of the Euclidean length for five wadis. In the figure, the regression lines produce horizontal lines and positive slopes. If the lines produce positive slopes, the average junction angles increase as tributary junctions move further downstream.

The estimated slopes of the regression lines created by the tributary junction angle measure as a function of the Euclidean length for the fifteen wadis are presented with their associated preexisting slopes in Figure $7 \mathrm{~b}$. The slopes of the regression lines formed by the tributary junction angle measure for thirteen wadis classified as rectangular networks range from 0.92 to 25.19 with an average of 11.24 . The slopes of the regression line based on the measure for the two wadis classified as parallel networks are 7.39 and 11.91 .

\section{Conclusions and Recommendations}

In this study, fifteen wadis in the mountainous region of the northeastern UAE and northern Oman are classified into different drainage network types by using three measures derived from scaling invariance. The slope of preexisting surfaces is also estimated to assess conditions under which wadis occur.

Thirteen wadis are classified as rectangular networks and two wadis are classified as parallel networks. Most wadis of the study area seem to represent rectangular networks developed in regions with cliffs, joints or faults. It was also found that rectangular networks in the UAE and Oman are characterized by steeper preexisting slopes than the same type of networks in other regions. The development of rectangular networks may be affected by other features that depend on climatic and other geologic conditions than the preexisting slopes. In the UAE and Oman, earth movements caused by plate tectonics have an effect on the formation of the mountains by characterizing the wadi networks representing rectangular networks. Also, climate conditions affect the development of the wadi networks featured by erosion and weathering processes. In other regions, river networks representing rectangular networks are developed in the system of cliffs or faults that produce the fractures. On the other hand, the steep preexisting slopes for wadis

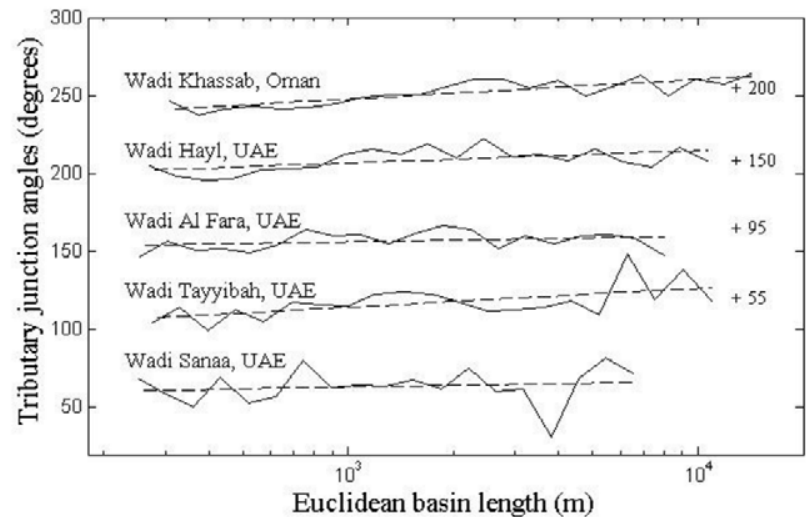

b

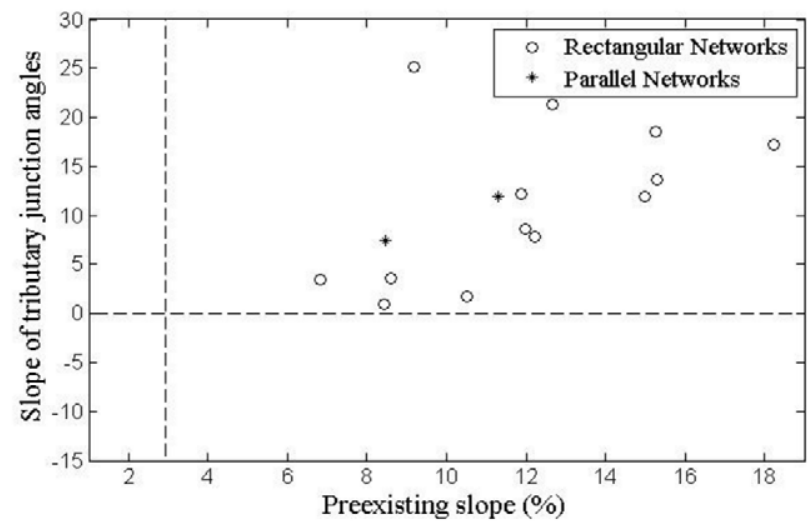

Figure 7: Figure (a) indicates the average value of the tributary junction angle $\psi_{b L, b L_{t}}(L)$ as a function of the Euclidean basin length for 5 wadis, and the dashed lines are regression ones fitted to the data. Figure (b) illustrates the relationship between the slope of the regression line generated by the tributary junction angle measure (slope of tributary junction angles) and the preexisting slope for all 15 wadis, and the thresholds are used to identify river network types. 
Citation: Jung K, Ouarda TBMJ (2015) Analysis and Classification of Channel Network Types for Intermittent Streams in the United Arab Emirates and Oman. J Civil Environ Eng 5: 183. doi:10.4172/2165-784X.1000183

classified as parallel networks seem to be consistent with the slopes of parallel networks in other regions.

The analysis of wadis representing rectangular networks is therefore required to identify conditions under which the network type develops since the preexisting slopes of the rectangular networks in the arid and semi-arid regions of the UAE and Oman are quite distinct from the same network type in other regions. It is also significant to investigate the conditions which influence the development of river networks in arid and semi-arid regions because the analysis of these conditions allows one to understand the hydrological processes that are involved in these locations where renewable water resources are limited.

In future research, the classification of river networks with their characteristics will be utilized in regional frequency analysis as new physiographical features to improve the accuracy of the frequency analysis procedures. Regional frequency analysis procedures are commonly used for the design of irrigation and groundwater recharge dams in arid and semi-arid regions. In the UAE alone, over 140 recharge dams have been built and more are being developed. It is important to develop regional procedures that are adapted to arid and semi-arid regions. Nevertheless, very little effort has focused on the development of regional frequency analysis procedures for such regions. The use of drainage network types and features as physiographical characteristics during the delineation step may lead to the identification of better homogenous regions and the improvement of design quantile estimation.

\section{Acknowledgements}

The financial support provided by Masdar Institute of Science and Technology is gratefully acknowledged.

\section{References}

1. Al-Nuaimi H, Al-Hammadi M, Sherif M, Al-Mahmoudi A (2003) Landforms and water resources in the United Arab Emirates. Allied Publisher, pp. 25-37.

2. Basha G, Ouarda TBMJ, Marpu PR (2015) Long-term projections of temperature, precipitation and soil moisture using non-stationary oscillation processes over the UAE region. Int J Climatol.

3. FAO (1997) Irrigation in the near East region in fiures. Water Report 9.

4. Niranjan Kumar K, Ouarda TBMJ (2014) Precipitation variability over UAE and global SST teleconnections. J Geophys Res-Atmos 119.

5. Fisher M (1994) Another look at the variability of desert climates, using examples from Oman. Glob Ecol Biogeogr Lett 4: 79-87.

6. Luedeling E, Buerkert A (2008) Typology of oases in northern Oman based on Landsat and SRTM imagery and geological survey data. Remote Sens Environ 112: $1181-1195$.

7. Sherif M, Akram S, Shetty A (2009) Rainfall analysis for the northern wadis of United Arab Emirates: A case study. J Hydrol Eng 14: 535-544.

8. Glennie KW (2005) The geology of the Oman Mountains: an outline of their origin. Scientific Press, Beaconsfield, Bucks, UK.

9. Ouarda TBMJ, Charron C, Niranjan Kumar K, Marpu PR, Ghedira H, et al (2014) Evolution of the rainfall regime in the United Arab Emirates. J Hydrol 514: 258-270.

10. Parvis M (1950) Drainage Pattern significance in airphoto identification of soils and bedrocks. Photogramm Eng 16: 375-409.

11. Howard AD (1967) Drainage analysis in geologic interpretation: a summation. Am Assoc Pet Geol Bull 51: 2246-2259.

12. Zernitz ER (1932) Drainage patterns and their significance. J Geol 40: 498-521.

13. Phillips LF, Schumm S (1987) Effect of regional slope on drainage networks. Geology 15: 813-816.

14. Argialas DP, Lyon JG, Mintzer OW (1988) Quantitative description and classification of drainage patterns. Photogramm Eng Remote Sens 54: 505-509.
15. Ichoku C, Chorowicz J (1994) A numerical approach to the analysis and classification of channel network patterns. Water Resour Res 30: 161-174.

16. Mejia Al, Niemann JD (2008) Identification and characterization of dendritic, parallel, pinnate, rectangular, and trellis networks based on deviations from planform self-similarity. J Geophys Res 113

17. Kim JC, Jung K (2015) Fractal Tree Analysis of Drainage Patterns. Water Resour Manage 29: 1217-1230

18. Mosley MP (1972) An experimental study of rill erosion. MS thesis Colorado State Univ Fort Collins 99.

19. Jung K, Niemann JD, Huang $X(2011)$ Under what conditions do parallel river networks occur? Geomorphol 132: 260-271.

20. Marra, WA, Kleinhans MG, Addink EA (2014) Network concepts to describe channel importance and change in multichannel systems: test results for the Jamuna River, Bangladesh. Earth Surf Process Landf 39: 766-778.

21. Julien PY (2010) Erosion and sedimentation. Cambridge Univ Press, p. 371.

22. An S, Julien PY (2014) Three-dimensional modeling of turbid density currents in Imha Reservoir, South Korea. J Hydraul Eng 140.

23. Chokmani K, Ouarda TBMJ (2004) Physiographical space-based kriging for regional flood frequency estimation at ungauged sites. Water Resour Res 40 W12514.

24. Shu C, Ouarda TBMJ (2007) Flood frequency analysis at ungauged sites using artificial neural networks in canonical correlation analysis physiographic space. Water Resour Res 43.

25. Ouarda TBMJ, Shu C (2009) Regional low-flow frequency analysis using single and ensemble artificial neural networks. Water Resour Res 45.

26. Chebana F, Ouarda TBMJ (2008) Depth and homogeneity in regional flood frequency analysis. Water Resour Res 44: W11422.

27. Zevenbergen LW, Thorne CR (1987) Quantitative analysis of land surface topography. Earth Surf Process Land 12: 47-56.

28. Mitášová H, Hofierka J (1993) Interpolation by regularized spline with tension: II. Application to terrain modeling and surface geometry analysis. Math Geol 25: 657-669.

29. Evans IS (1972) General geomorphometry, derivatives of altitude, and descriptive statistics. Spatial Anal Geomorphology 17-90.

30. Gardiner V, Park C (1978) Drainage basin morphometry review and assessment. Prog Phys Geogr 2: 1-35.

31. Tokunaga $E$ (1978) Consideration on the composition of drainage networks and their evolution. Tokyo Metropolitan Univ 13: 1-27.

32. Jung K, Marpu PR, Ouarda TBMJ (2015) Improved classification of drainage networks using junction angles and secondary tributary lengths. Geomorphology 239: 41-47.

33. Turcotte DL (1997) Fractals and chaos in geology and geophysics. Cambridge Univ Press.

34. Rodríguez-Iturbe I, Rinaldo A (2001) Fractal river basins: chance and selforganization. Cambridge Univ Press.

35. Donadio C, Magdaleno F, Mazzarella A, Kondolf GM (2014) Fractal Dimension of the Hydrographic Pattern of Three Large Rivers in the Mediterranean Morphoclimatic System: Geomorphologic Interpretation of Russian (USA), Ebro (Spain) and Volturno (Italy) Fluvial Geometry. Pure Appl Geophys 1-10.

36. Aspinall S, Hellyer P (2005) The Emirates: a natural history. Trident Press, pp. 41-62. 